\title{
Pengaruh Bauran Pemasaran Terhadap Perpindahan Merek Pelanggan Restoran Cepat Saji di Karawang Menggunakan Metode Markov Chains dan Game Theory
}

\section{Effect of Marketing Mix on Customer Brand Transfer Fast Food Restaurant in Karawang Using Markov Chains and Game Theory Method}

\author{
Rianita Puspa Sari ${ }^{1 *}$, Ahmad Surahman ${ }^{1}$, Aditia Ayu Rahma Nabila ${ }^{1}$ \\ ${ }^{1}$ Program Studi Teknik Industri, Universitas Singaperbangsa Karawang, Jl. H. S. Ronggowaluyo, Telukjambe \\ Timur, Karawang 41361, Indonesia
}

Diterima: 6 Desember, 2018 / Disetujui: 13 Februari, 2019

\begin{abstract}
As an area that has evolved into one of the industrial cities in Indonesia, Karawang has experienced rapid growth, especially in the fields of industry and business. This causes a change in lifestyle so that modern society is born that is synonymous with consumptive behavior patterns which result in new needs that are presented practically in people's lives, one of which is restaurant food needs so that growth presence of fast food restaurants in Karawang. Competition between fast food restaurants can result in the brands switch to customers, so marketing mix strategy (9P) is needed (Product, Price, Promotion, Place, People, Process, Physical Evidence, Packaging, Payment). This study aims to analyze the effect of the marketing mix on brand movement, the rate of movement of fast food restaurant brands $(X, Y$, and $Z)$ at Karawang, and the right strategy for companies to win the competition. The Markov Chains method is used to predict the market share of a product from the level of transfer of fast-food restaurant brands in Karawang, while Game Theory is to determine the right strategy in the marketing mix in the face of shifting customer brands. Research results obtained from 113 respondents who are valid and reliable, with the relationship of the two low variables are negative at -0.083 interpreting that the marketing mix correlation with brand displacement has an inverse relationship so that the marketing mix of fast food restaurants increases, the customer's brand shift will be lower. The brand transfer rate is predicted to have a market share in the coming year of $33.2 \% \mathrm{X}, 36.2 \% \mathrm{Y}$ and $30.6 \% \mathrm{Z}$ with competitive strategies that can be done by increasing the Promotion and Location of Fast Food Restaurants.
\end{abstract}

Keywords: Marketing Mix, Brand Switching, Markov Chains, Game Theory

\begin{abstract}
ABSTRAK
Karawang sebagai suatu daerah yang telah berevolusi menjadi salah satu kota industri di Indonesia mengalami pertumbuhan yang begitu pesat, terutama dalam bidang perindustrian dan bisnis. Hal ini menyebabkan terjadinya perubahan gaya hidup, sehingga lahirlah suatu masyarakat modern yang identik dengan pola perilaku konsumtif yang mengakibatkan kebutuhan-kebutuhan baru yang tersaji secara praktis dalam kehidupan masyarakat, yang salah satunya kebutuhan restoran makanan, sehingga semakin banyak kehadiran restoran cepat saji di Karawang. Persaingan antar restoran cepat saji dapat mengakibatkan perpindahan merek pada pelanggan, sehingga diperlukan strategi bauran pemasaran 9P yang tepat (Product, Price, Promotion, Place, People, Process, Physical Evidence, Packaging, Payment). Penelitian ini bertujuan untuk menganalisis pengaruh bauran pemasaran terhadap perpindahan merek, tingkat perpindahan merek restoran cepat saji (X, Y, dan Z) di karawang, serta strategi yang tepat bagi perusahaan dalam memenangkan persaingan. Metode Markov Chains digunakan untuk memprediksi pangsa pasar suatu produk dari tingkat perpindahan merek restoran cepat saji di Karawang, sedangkan Game Theory untuk menentukan strategi yang tepat pada bauran pemasaran dalam menghadapi perpindahan merek pelanggan. Hasil Penelitian didapatkan dari 113 responden yang valid dan reliabel, dengan hubungan kedua variabel rendah bersifat negatif sebesar -0.083 berinterpretasi bahwa korelasi bauran pemasaran dengan perpindahan merek memiliki hubungan terbalik sehingga jika bauran pemasaran yang dilakukan restoran cepat saji semakin meningkat maka perpindahan merek pelanggan akan semakin rendah. Adapun tingkat perpindahan
\end{abstract}

"email: rianita.puspasari@ft.unsika.ac.id 
merek diprediksikan memiliki pangsa pasar ditahun mendatang sebesar $33.2 \% \mathrm{X}, 36.2 \% \mathrm{Y}$ dan $30.6 \% \mathrm{Z}$ dengan strategi persaingan yang dapat dilakukan dengan meningkatan promosi dan lokasi restoran cepat saji.

Kata Kunci: Bauran pemasaran, Perpindahan merek, Markov Chains, Game Theory

\section{PENDAHULUAN}

Era globalisasi menyebabkan perubahan pola kehidupan sosial dan gaya hidup masyarakat dengan pola perilaku konsumtif dengan gaya hidup serba instan. Perilaku konsumtif mendorong munculnya industriindustri yang memenuhi kebutuhan masyarakat, salah satunya industri di bidang makanan cepat saji. Pada awalnya industri makanan cepat saji ini hanya sebagai sebuah pelengkap kebutuhan, namun seiring dengan perkembangan sosialbudaya menjadikannya tren di kalangan masyarakat, terutama pada masyarakat perkotaan. Karawang sebagai salah satu daerah di Indonesia yang telah berevolusi menjadi kota industri, dengan dinamika penduduk yang bekerja dikantor, bahkan dengan zaman media sosial, masyarakat ikut merasakan pengaruh tren pada restoran cepat saji, sehingga minat beli restoran cepat saji di Karawang menjadi tinggi.

Melihat kondisi ini, maka banyak para pelaku usaha restoran cepat saji yang menanamkan usaha di Karawang, seperti restoran $\mathrm{X}, \mathrm{Y}, \mathrm{Z}$ dan masih banyak lainnya. Hal ini tentu menyebabkanan lahirnya persaingan antar restoran cepat saji di Karawang. Hal ini juga menuntut perusahaan berinovasi demi kelangsungan usahanya. Keanekaragaman hasil inovasi yang ditawarkan memberikan manfaat terhadap konsumen untuk dapat lebih selektif dalam melakukan pembelian. Namun, di sisi lain hal ini dapat menjadi bumerang bagi pelaku usaha karena menyebabkan timbulnya perilaku perpindahan merek di kalangan pelanggan. Perpindahan merek (brand switching) adalah karakteristik pola pembelian dengan perubahan atau pergantian dari satu merek ke merek yang lain (Peter dan Olson, 2010). Oleh karena itu, perusahaan haruslah mempunyai strategi yang tepat dalam memenangkan persaingan, terutama di bidang pemasaran. Lebih jauh lagi, perusahaan akan mampu mengenali perilaku pelanggan dan dapat memengaruhi perilaku beli pada pelanggan dengan strategi bauran pemasaran (marketing mix). Bauran pemasaran adalah seperangkat alat yang digunakan oleh perusahaan secara terus-menerus dalam mencapai tujuan perusahaan di pasar sasaran (Kotler dan Armstrong, 2016).
Penelitian terdahulu mengenai pengaruh bauran pemasaran terhadap perilaku perpindahan merek mie instan di Kota Kediri, menggunakan metode regresi linear menemukan bahwa bauran pemasaran memiliki pengaruh terhadap perpindahan merek khususnya pada harga, promosi, dan distribusi produk (Astuti, 2014). Penelitian terdahulu mengungkapkan bahwa terdapat pengaruh signifikan antara atribut produk dalam perilaku perpindahan merek (Venkatesakumar, Ramkumar dan Rajan, 2008). Lebih jauh lagi, dikemukakan bahwa sekelompok atribut produk dapat memicu keinginan untuk berpindah dari merek yang saat ini digunakan (Venkatesakumar, Ramkumar dan Rajan, 2008).

Markov chains merupakan salah satu metode yang digunakan untuk memprediksi pangsa pasar suatu produk pada periode saat ini sebagai dasar untuk memprediksi pangsa pasar yang akan datang (Nofiyah, Hendikawati dan Mariani, 2013). Untuk membuat strategi yang tepat dalam menghadapi persaingan maka dapat dihitung secara probabilitas melalui metode game theory. Game theory adalah sebagai cabang matematika yang membahas aspek persaingan dan kolaborasi yang timbul di antara perusahaan atau "pemain" (Arsenyan, Büyüközkan dan Feyzioğlu, 2011).

Penelitian terdahulu melihat bauran pemasaran hanya dari 4P, dan hubungan pengaruh tanpa mengetahui tingkat perpindahan merek akibat bauran pemasaran, serta strategi yang tepat dalam memenangkan persaingan (Astuti, 2014; Wijaya, Fauzi dan Sunarti, 2014; Indarwati dan Untarini, 2017). Penelitian ini bertujuan untuk mengetahui pengaruh pada setiap elemen bauran pemasaran 9P (Product, Price, Promotion, Place, People, Process, Physical Evidence, Packaging, Payment) terhadap perpindahan merek, selain itu salah satu cara untuk mengetahui tingkat perpindahan merek akibat bauran pemasaran pada restoran cepat saji di Karawang dapat diidentifikasi dengan metode markov chains, dan strategi memenangkan persaingan untuk perpindahan merek diidentifikasi dengan metode game theory. 


\section{METODOLOGI}

Penelitian ini menggunakan pendekatan secara kuantitatif. Berdasarkan pada tujuannya penelitian ini digolongkan ke dalam penelitian korelasional, yaitu penelitian yang melibatkan pengumpulan data untuk menentukan apakah, dan sampai sejauh mana, ada hubungan antara dua atau lebih variabel yang dapat dihitung (Leedy dan Ormrod, 2015). Berdasarkan manfaatnya, penelitian ini merupakan penelitian terapan, yaitu salah satu jenis penelitian yang bertujuan untuk memberikan solusi atas permasalahan tertentu secara praktis (Maryati dan Suryawati, 2015).

Penelitian dilakukan di Restoran X, Y, Z di cabang Galuh Mas Karawang. Restoran cepat saji ini berlokasi di Jl. Galuh Mas Raya, Sukaharja, Telukjambe Timur, Kabupaten Karawang, Provinsi Jawa Barat.

Data primer dikumpulkan langsung dari hasil penyebaran kuesioner kepada responden yang terdiri atas variabel-variabel Bauran pemasaran 9P yang meliputi product, price, place, promotion, people, process, physicalevidence, packaging dan payment.

Populasi terdiri atas obyek/subyek yang mempunyai kualitas dan karakteristik tertentu yang ditetapkan oleh peneliti untuk dipelajari dan kemudian ditarik kesimpulannya, sementara sampel merupakan bagian dari jumlah dan karakteristik yang dimiliki oleh populasi (Sugiyono, 2011). Pada penelitian ini yang menjadi populasi adalah masyarakat Karawang, pada segmentasi pasar remaja-dewasa sekitar usia 15-34 tahun dengan jumlah penduduk sebanyak 809.557 jiwa (Badan Pusat Statistik, 2017). Pada penelitian ini, berdasarkan rumus slovin sampel yang diperlukan peneliti sebanyak 100 orang penduduk karawang berusia 15-34 tahun.

Analisis data dilakukan setelah data hasil responden terkumpulkan. Sebelum melakukan analisis data untuk mengetahui pengaruh bauran pemasaran terhadap perpindahan merek pelanggan restoran cepat saji di karawang dengan menggunakan metode markov chains dan game theory, data hasil kuesioner responden diuji terlebih dahulu dengan menggunakan perangkat lunak Statistic Product and Service Solution (SPSS). Langkah ini bertujuan untuk mengetahui sejauh mana variabel/instrumen yang dipakai dalam kuesioner sesuai dengan permasalahan sehingga bisa dikatakan valid (akurat) dan mengetahui apakah teknik pengambilan data sesuai dengan permasalahan (reliabel). Apabila data telah valid dan reliabel, selanjutnya data kuesioner tersebut dianalisis dengan uji korelasi, serta metode markov chains dan game theory menggunakan perangkat lunak WINQSB. Akhirnya, hasil penelitian diperoleh sesuai dengan rumusan dan tujuan penelitian. Kerangka pengolahan data pada penelitian dapat dilihat pada Gambar 1.

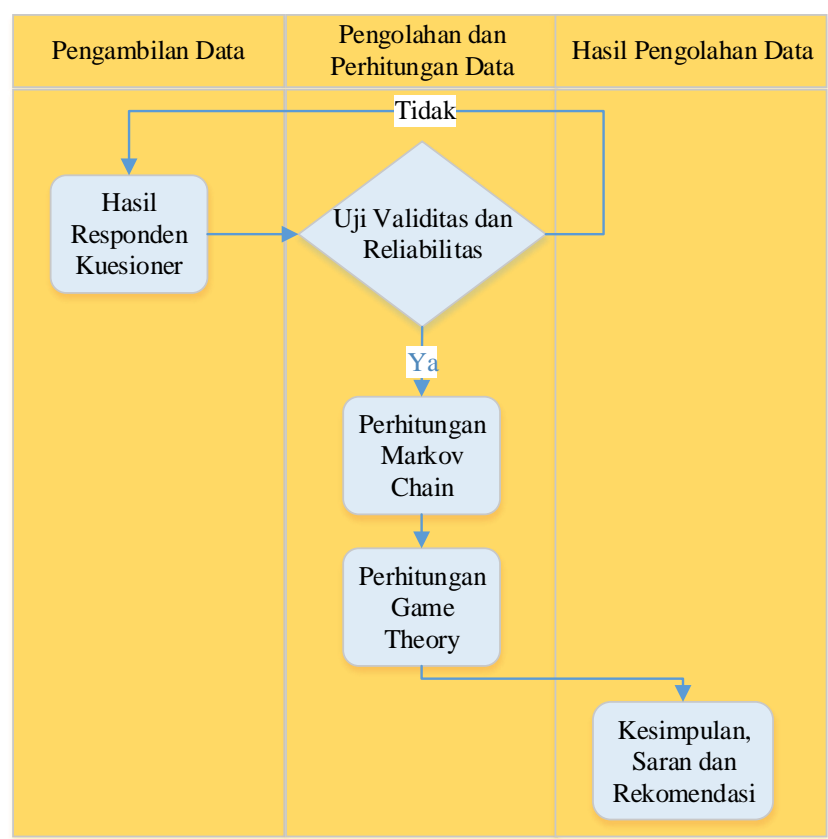

Gambar 1. Flowchart Pengolahan Data 


\section{HASIL DAN PEMBAHASAN}

Data yang digunakan dalam penelitian ini ialah data primer yang dikumpulkan dari hasil penyebaran kuesioner, selama 2 bulan yang dimulai dari 25 Agustus sampai dengan 26 Oktober 2018, yang disebarkan kepada masyakarat Kabupaten Karawang. Secara statistika deskriptif pada Tabel 1, karakteristik responden merupakan kategori usia remajadewasa didominasi perempuan dengan rentang usia 21-25 tahun, dengan status pekerjaan sebagai mahasiswa/pelajar, serta perpindahan merek restoran cepat saji dikarenakan faktor product, promotion serta place restoran cepat saji.

Sebelum data diolah dan dianalisis dengan menggunakan metode markov chains dan game theory, maka data terlebih dahulu diuji kecukupan data, validitas dan reliabilitas data, serta uji korelasi dengan menggunakan perangkat lunak SPSS. Semua data responden dari hasil SPSS dinyatakan valid dan reliabel dengan nilai cronbach alpha 0.893 .

\subsection{Uji Korelasi}

Uji korelasi dilakukan untuk mengetahui adanya pengaruh bauran pemasaran terhadap perpindahan merek pada restoran cepat saji, pada Tabel 2 diketahui bahwa pengaruh bauran pemasaran terhadap perpindahn merek yang memiliki hubungan korelasi negatif yang rendah sebesar -0.083 sehingga terjadi penolakan $H_{0}$ yang berinterpretasi bahwa strategi bauran pemasaran tidak memiliki pengaruh dengan perpindahan merek pada pelanggan restoran cepat saji. Korelasi negatif tersebut menunjukkan bahwa bauran pemasaran dengan perpindahan merek berhubungan terbalik dimana jika nilai bauran pemasaran meningkat maka perpindahan merek pada pelanggan akan rendah, begitu juga sebaliknya. Dengan demikian, restoran cepat saji di Karawang harusnya berupaya meningkatkan strategi bauran pemasarannya supaya tidak terjadi perpindahan merek pada restoran cepat saji.

\subsection{Perhitungan Markov Chains}

Berdasarkan data-data perpindahan restoran cepat saji di Karawang, dilakukan perhitungan peluang transisi sehingga didapat hasil pada Tabel 3. Kemudian, data digunakan untuk mengetahui peluang terjadinya perpindahan cepat saji di Karawang pada periode selanjutnya menggunakan perangkat lunak WINQSB dengan hasil pada Gambar 2. Berdasarkan Gambar 2, nilai market share pada tiga restoran cepat saji di Karawang, ialah:

a. $33.2 \%$ untuk X,

b. $36.2 \%$ untuk Y; dan

c. $30.6 \%$ untuk $\mathrm{Z}$

Disimpulkan bahwa $Z$ merupakan restoran cepat saji yang memeliki market share terkecil diantara $X$ dan $Y$.

\subsection{Perhitungan Game Theory}

Dalam penelitian ini juga menggunakan perhitungan game theory yang bertujuan untuk membuat dan menentukan strategi bersaing bagi restoran cepat saji bila terjadi perpindahan merek, dimana strategi yang dibuat berdasarkan pada variabel 9P bauran pemasaran. Berdasarkan data dari responden kuesioner diperoleh kalkukasi nilai restoran cepat saji terhadap 9P bauran pemasaran, dilakukan perhitungan dan pengolahan dengan perangkat lunak WINQSB, sehingga diperoleh hasil nilai payoff game theory seperti pada Gambar 3 analisis matriks payoff menunjukan bahwa bahwa restoran cepat saji $Z$ saat bersaing dengan $\mathrm{X}$ sadle pointnya berada pada variebel promosi dengan nilai $-0,404$ sehingga $\mathrm{Z}$ harus meningkatkan kegiatan promosinya agar tidak terjadi perpindahan merek pelanggannya, sedangkan saat bersaing dengan $Y$ titik sadle pointnya berada pada variabel place dengan nilai $-0,265$ sehingga $\mathrm{Z}$ harus meningkatkan dalam sisi lokasinya.

Tabel 1. Karakteristik Responden

\begin{tabular}{ccc}
\hline NO & KARAKTERISTIK & PERSENTASE \\
\hline Jenis Kelamin & Laki-Laki & $43 \%$ \\
$\mathbf{1}$ & Perempuan & $\mathbf{5 7 \%}$ \\
2. & \\
Rentang Usia & $17 \%$ \\
$\mathbf{1}$ & 15-20 Tahun & $\mathbf{6 8 \%}$ \\
$\mathbf{2}$ & $\mathbf{2 1 - 2 5}$ Tahun & \\
\hline
\end{tabular}




\begin{tabular}{|c|c|c|}
\hline NO & KARAKTERISTIK & PERSENTASE \\
\hline 3. & 26-30 Tahun & $15 \%$ \\
\hline 4. & 31-34 Tahun & $0 \%$ \\
\hline \multicolumn{3}{|c|}{ Status Pekerjaan } \\
\hline 1. & Mahasiswa/Pelajar & $63 \%$ \\
\hline 2. & Pekerja & $37 \%$ \\
\hline \multicolumn{3}{|c|}{ Perpindahan Merek dikarenakan Bauran Pemasaran: } \\
\hline 1. & Product & $37 \%$ \\
\hline 2. & Price & $11 \%$ \\
\hline 3. & Promotion & $22 \%$ \\
\hline 4. & Place & $17 \%$ \\
\hline 5. & People & $7 \%$ \\
\hline 6. & Process & $2 \%$ \\
\hline 7. & Physical Evidence & $1 \%$ \\
\hline 8. & Packaging & $1 \%$ \\
\hline 9. & Payment & $2 \%$ \\
\hline
\end{tabular}

Tabel 2. Hasil Uji Korelasi dengan SPSS

\begin{tabular}{|ll|r|r|}
\hline \multicolumn{3}{|c|}{ Correlations } \\
\hline & & $\begin{array}{c}\text { Bauran } \\
\text { Pemasaran }\end{array}$ & $\begin{array}{c}\text { Perpindahan } \\
\text { Merek }\end{array}$ \\
\hline BauranPemasaran & Pearson Correlation & 1 & -.083 \\
& Sig. (2-tailed) & & .381 \\
& $N$ & 113 & 113 \\
\hline Perpindahanmerek & Pearson Correlation & -.083 & 1 \\
& Sig. (2-tailed) & .381 & 113 \\
\hline \hline
\end{tabular}

Tabel 3. Peluang Transisi Restoran Cepat Saji di Karawang

\begin{tabular}{cccc}
\hline \multirow{2}{*}{ Dari- } & \multicolumn{3}{c}{ Ke- } \\
\cline { 2 - 4 } & X & Y & Z \\
X & $\mathbf{0 . 0 3 2}$ & $\mathbf{0 . 5 4 8}$ & $\mathbf{0 . 4 1 9}$ \\
Y & $\mathbf{0 . 4 8 1}$ & $\mathbf{0 . 0 7 4}$ & $\mathbf{0 . 4 4 4}$ \\
Market Share & $\mathbf{0 . 4 8 2}$ & $\mathbf{0 . 4 6 4}$ & $\mathbf{0 . 0 5 4}$ \\
\hline
\end{tabular}

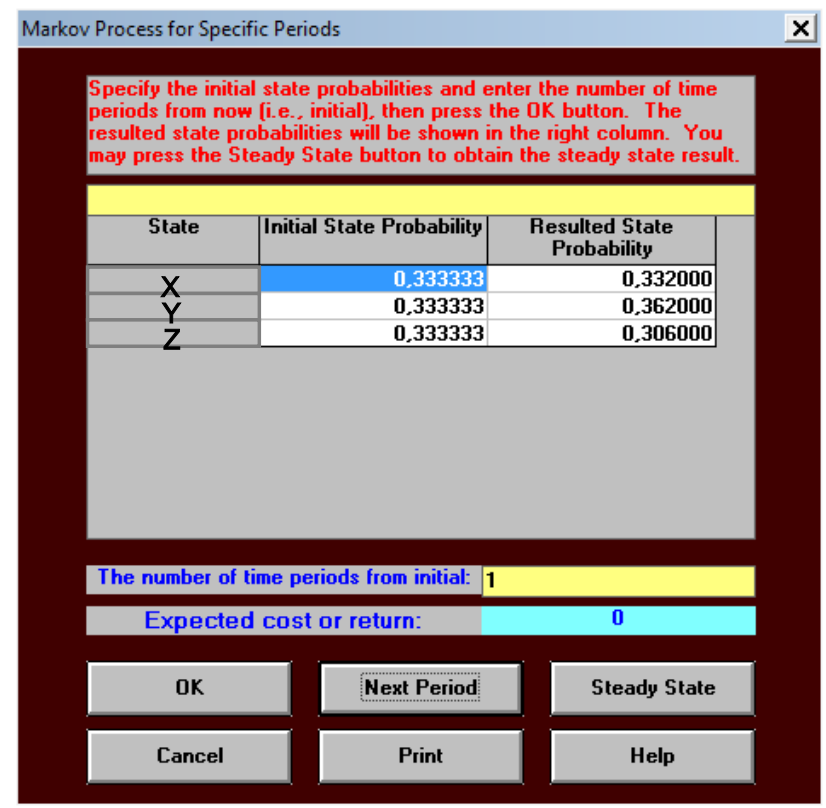

Gambar 2. Hasil Markov Chains dengan WINQSB ke-1 


\begin{tabular}{|c|c|c|c|}
\hline $\begin{array}{c}\text { 11-24-2018 } \\
\text { Criterion }\end{array}$ & $\begin{array}{c}\text { Best } \\
\text { Decision }\end{array}$ & $\begin{array}{l}\text { Decision } \\
\text { Value }\end{array}$ & \\
\hline Maximin & $z$ & $\$ 265$ & \\
\hline Maximax & $x$ & $\$ 404$ & \\
\hline Hurwicz $[p=0,5]$ & $x$ & Rp334 & \\
\hline Minimax Regret & $x$ & $\$ 78$ & \\
\hline Expected Value & $Y$ & Rp323 & \\
\hline Equal Likelihood & $Y$ & Rp323 & \\
\hline Expected Regret & $Y$ & Rp24 & \\
\hline Expected Value & without any & Information = & Rp323 \\
\hline Expected Value & with Perfect & Information = & Rp348 \\
\hline Expected Value & of Perfect & Information = & Rp24 \\
\hline
\end{tabular}

Gambar 3. Hasil Analisis Game Theory dengan Perangkat Lunak WINQSB

\section{SIMPULAN}

Berdasarkan hasil penelitian, bauran pemasaran dengan perpindahan merek berhubungan terbalik dimana jika nilai bauran pemasaran meningkat maka perpindahan merek pada pelanggan juga akan rendah, begitu juga sebaliknya. Maka, restoran cepat saji di Karawang khususnya Z, Y dan X untuk dapat meningkatkan aspek-aspek bauran pemasaran terutama product, promotion dan place. Namun juga memperhatikan aspek yang lainnnya baik dari segi price, people, process, physical evidence, packaging, dan payment.

Restoran cepat saji yang memiliki market share paling rendah dari hasil markov chains adalah Z. Pada analisis game theory, agar tidak terjadi perpindahan merek pada pelanggan, disarankan bahwa saat restoran $\mathrm{Z}$ bersaing dengan $X$ harus meningkatkan bidang promosinya, sedangkan saat restoran $\mathrm{Z}$ saat bersaing dengan $\mathrm{Y}$ harus mengatur strategi dalam bidang lokasi. Hal-hal tersebut perlu dilakukan untuk mengurangi terjadinya perpindahan merek pelanggan yang lebih banyak.

\section{DAFTAR PUSTAKA}

Arsenyan, J., Büyüközkan, G. dan Feyzioğlu, O. (2011) "Modelling Collaboration Formation with a Game Theory Approach," in Proceedings of the World Congress on Engineering. London.

Astuti, I. Y. (2014) "Pengaruh Variabel Bauran Pemasaran Terhadap Perilaku Perpindahan Merek Mie Instan Merek Lain Ke Mie instan Merek Indomie Di Kota Kediri," Jurnal Cendekia, 12(1), hal. 40-51.

Badan Pusat Statistik (2017) Karawang Dalam Angka. Karawang. Tersedia pada: https://karawangkab.bps.go.id/publicatio n/2017/08/17/258839c82b4aaf001be0f08 f/kabupaten-karawang-dalam-angka2017.html.

Indarwati, Y. dan Untarini, N. (2017) "Pengaruh Ketidakpuasan terhadap Keputusan Perpindahan Merek dengan Kebutuhan Mencari Variasi sebagai Variabel Moderasi," Jurnal Ilmu Manajemen, 5(1).

Kotler, P. dan Armstrong, G. (2016) Principles of Marketing. 16 ed. London: Pearson Education Limited.

Leedy, P. D. dan Ormrod, J. E. (2015) Practical Research Planning and Design. 11 ed. Harlow: Pearson Education Limited.

Maryati, K. dan Suryawati, J. (2015) Sosiologi. 3 ed. Jakarta: Esis.

Nofiyah, N., Hendikawati, P. dan Mariani, S. (2013) "Analisis Markov Chain untuk Forecasting Pangsa Pasar Handphone dan Programnya," Unnes Journal of Mathematics, 2(2), hal. 110-115.

Peter, J. P. dan Olson, J. C. (2010) Consumer Behavior and Marketing Strategy. 9 ed. New York: McGraw-Hill/Irwin.

Sugiyono (2011) Metode Penelitian Kuantitatif Kualitatif dan $R \& D$. Bandung: Alfabeta.

Venkatesakumar, R., Ramkumar, D. dan Rajan, P. T. (2008) "Perception of Product Attributes in Brand Switching BehaviourAn Explanation through Multidimensional Scaling," Management and Labour Studies, 33(1), hal. 142-156.

Wijaya, Y. S., Fauzi, D. A. dan Sunarti (2014) 
"Pengaruh Atribut Produk terhadap

Administrasi Bisnis, 12(2), hal. 1-7.

Keputusan Perpindahan Merek," Jurnal 